\title{
PLANO NACIONAL DE EDUCAÇÃO: ANÁLISE DA INCLUSÃO DO JOVEM \\ NO ENSINO MÉDIO
}

Vanderlei Balbino Costa

Halline Mariana Santos Silva

RESUMO: O presente artigo é resultado das nossas reflexões acerca da Lei $\mathrm{n}^{\circ} 13.005$ que estabelece o Plano Nacional de Educação (PNE), aprovado em 25 de junho de 2014. No respectivo estudo discutimos sobre as metas propostas para a inclusão dos jovens estudantes com deficiência no Ensino Médio até 2024. Nossos objetivos nessas reflexões teóricas foram: analisar a Lei n ${ }^{\circ} 13.005$ de 25 de junho de 2014 que estabelece o Plano Nacional de Educação - PNE (2014-2024), procurando avaliar se o referido documento reúne condições que possibilite implementar a meta proposta para a inclusão dos jovens estudantes com deficiência no Ensino Médio. Nesse itinerário nos guiamos pela pesquisa qualitativa e análise documental. Os resultados preliminares nos mostraram que são grandes os desafios para implementar a referida meta. Consideramos relevante a ampliação de estudos que possam acompanhar a execução do PNE até 2024.

PALAVRAS-CHAVE: Ensino Médio. Meta 4. Deficiência. Juventude. Políticas Educacionais.

\section{NOTAS INTROdUtórias}

Os anos de 1990 foram marcados por diversas transformações, principalmente no que concerne à educação especial voltada às pessoas com deficiência no cenário mundial. Nesta mesma década, realizou-se em Jomtien - Tailândia, a Conferência Mundial de Educação Para Todos: satisfação das necessidades básicas de aprendizagem, promovida pelo Banco Mundial, Organização das Nações Unidas para a Educação, a Ciência e a Cultura (UNESCO), o Fundo das Nações Unidas para a Infância (UNICEF) e o Programa das Nações Unidas para o Desenvolvimento (PNUD). Muitos países se fizeram presentes nessas convenções, se comprometendo com a promoção da educação no sentido de garantir acesso a todos ao ensino público. Na esfera global, o maior movimento de educação borbulhou na Espanha: A Conferência Mundial sobre Necessidades Educacionais Especiais: acesso e qualidade, promovida pela UNESCO, que resultou na conhecida Declaração de Salamanca (1994). Nessa declaração 92 Países e 25 organizações não governamentais, signatários se comprometeram a erradicar os principais problemas que envolvem a educação das pessoas com necessidades educativas especiais, menores de rua, diferentes etnias, dentre outros. (UNESCO, 1994).

Se guinarmos nosso olhar para o contexto educacional brasileiro, é notório assinalar que esse período, foi marcado por importante acontecimento: a Constituição Federal de 1988, em seu artigo 205, que estabelece a educação como direito de todos e dever do Estado e da família, de promover e incentivar a educação em colaboração com a sociedade. No artigo 208, no parágrafo III, indica o dever do Estado com educação, mediante ao atendimento educacional especializado às pessoas com deficiência, preferencialmente na rede regular de ensino. (BRASIL, 1988). Ressaltamos ainda a promulgação da Lei de Diretrizes e Bases da Educação Nacional (LDBEN 9394/96), que pela primeira vez na história da educação brasileira fez aprovar um capítulo específico sobre educação especial. No artigo 58 da referida lei, sugere que, quando necessário, caberá ao Estado oferecer serviços de apoio especializado aos estudantes com deficiência, incluídos na escola regular, independentemente do nível de escolaridade que esses estão cursando. (BRASIL, 1996).

No que concerne à educação especial, o Ministério da Educação - MEC fez aprovar o documento intitulado: "A Política Nacional para a Educação Especial na Perspectiva da Educação 
Inclusiva". Neste documento, o MEC estabelece metas para a promoção da inclusão às pessoas com necessidades educativas especiais, negros, indígenas, educação de jovens e adultos e educação infantil. (BRASIL, 2008).

Em relação à promoção da inclusão escolar das pessoas com deficiência, a Lei 7.853, aprovada em 24 de outubro de 1989 e promulgada em 1999, atribui crime à escola que negar a matrícula de estudantes com deficiência. Leis, Decretos e Legislações prescrevem que o direito à educação é um elemento inviolável a todas as pessoas, e aqueles que violarem este direito poderão responder criminalmente. (BRASIL, 1999).

Os referenciais propostos nos últimos anos são incisivos em afirmar que os direitos humanos é uma questão de justiça social. À literatura que enfatiza essa questão, assinala que "há certa perplexidade ao observar a forma como esses direitos vêm se transformando em uma linguagem política sendo utilizados de acordo com a conveniência e o contexto político do momento". (SANTOS,2009, p. 39). Não são recentes os discursos de que a educação é um direito social. Atualmente, nota-se que há nas fileiras do poder público a intensificação de discursos alusivos à promoção da educação de qualidade para todas as pessoas. Inserem nesses grupos os jovens estudantes com deficiência, alijados por muitos anos desse importante direito de frequentar à educação na sua idade cronológica correta. Historicamente, as pessoas com deficiência foram tratadas de forma segregada, não se respeitava as diferenças individuais de cada pessoa, seus desejos, suas potencialidades. No que concerne à inclusão dos estudantes com deficiência no Ensino Médio, essa exclusão é ainda muito significante, pois o que percebemos é uma quase total ausência de políticas do poder público frente a esse importante causa social.

À luz da literatura, vemos na Declaração Universal dos Direitos Humanos (ONU, 1948), um importante passo no sentido de implementar o processo de inclusão escolar dos estudantes com deficiência até 17 anos no Ensino Médio. Cumpre-nos ressaltar que a Declaração Universal dos Direitos Humanos (1948), atribui à educação o estado de direito universal. O direito à educação, o respeito aos Direitos Humanos e a efetivação da inclusão de grupos vulneráveis como: pessoas com deficiência, mulheres, jovens negros, crianças hospitalizadas, movimentos de trabalhadores sem-terra, comunidades ciganas, indígenas, quilombolas, circenses, dentre outras são exemplos da fragilidade política do Estado que não cumpre com os preceitos constitucionais dispostos nas declarações internacionais e constituições que garantem o direito à educação de todas as pessoas, independente se essas são ou estão em situação de deficiência. (ONU, 1948).

O mundo moderno, globalizado, sem fronteiras vive no atual momento algumas crises, mesmo porque, não há uma clara definição política frente às questões sociais como deficiência, raça, etnia, credo religioso, orientação sexual, gênero, dentre outros. Ao se referir a educação básica, em especial, quando falamos da inclusão dos jovens com deficiência no ensino médio, essa crise de identidade também se faz presente. Isso pode ser observado nos escritos que discutem a construção das identidades. "O sujeito assume identidades diferentes em diferentes momentos, identidades que não são unificadas ao redor de um eu coerente. Dentro de nós há identidades contraditórias, empurrando em diferentes direções, de tal modo que nossas identificações estão sendo continuamente deslocadas. Se sentirmos que temos uma identidade unificada desde o nascimento até a morte é apenas porque construímos uma como das histórias sobre nós mesmos ou uma confortadora narrativa do eu. (HALL, 1999, p. 13). Queremos afirmar que nossas identida- 
des não são únicas, homogêneas, concedidas e outorgadas. Ao contrário, ela, nossas identidades são construídas a partir das experiências que adquirimos ao longo das nossas vidas.

São muitas as questões que poderiam ser investigadas neste artigo. No entanto, a questão suleadora tem a intenção de indagar: Como os jovens foram compreendidos no novo Plano Nacional de Educação, bem como as metas propostas a serem implementadas no sentido de incluir os estudantes com deficiência no ensino médio até o ano de 2024. Assim, intencionamos analisar as possibilidades dessa meta em um município do Estado de Goiás, procurando refletir sobre o direito ao atendimento educacional especializado AEE, frente à inclusão escolar dos jovens estudantes com deficiência no ensino médio?

Nossos objetivos nessa investigação foram: analisar a Lei no 13.005 de 25 de junho de 2014 que estabelece o Plano Nacional de Educação - PNE (2014-2024) procurando discutir as metas propostas para a inclusão dos jovens estudantes com deficiência no Ensino Médio até 2024; identificar-se o PNE, reúne condições que possibilite implementar a meta proposta para a inclusão dos jovens estudantes com deficiência, bem como discutir se este documento dialoga com o que vem sendo produzido no campo acadêmico no que concerne as temáticas da inclusão e da juventude; averiguar se o Atendimento Educacional Especializado proposto pelo PNE vem dando conta de implementar a política de inclusão para os jovens com deficiência nas escolas da rede básica do município de Jataí/Go.

A opção neste artigo se deu pela pesquisa qualitativa, assim caracterizada. "à pesquisa qualitativa tem o ambiente natural como sua fonte direta de dados e o pesquisador como seu principal instrumento". (LUDKE E ANDRÉ, 1986, p. 11).

Neste artigo de reflexão, iremos também lançar mão da pesquisa documental aqui descrita. "os documentos representam ainda uma fonte natural de informação. Não são apenas uma fonte de informação contextualizada, mas surgem num determinado contexto e fornecem informações sobre esse mesmo contexto" (LUDKE E ANDRÉ, 1986, p. 39). Justifica-se o uso de documentos, considerando que no decorrer da pesquisa lançamos mão de decretos, resoluções, conferências e legislações que discutem à educação em suas várias dimensões.

\section{Análise do Plano Nacional de Educação: um olhar sobre as metas 3 e 4}

No que concerne a inclusão do jovem com deficiência no Ensino Médio, cumpre-nos assinalar que ainda é restrito o enfoque que se faz acerca desta temática. Todavia, ao mesmo tempo em que as discussões da educação como direito de todos avançavam do ponto de vista da legislação, os estudos que focam o sujeito jovem como objeto de análise também se ampliam gradativamente. Reflexões de cunho sociológico colocam outros aspectos no debate para além dos marcos biológicos e psicológicos que frequentemente são usados para caracterizar essa fase da vida.

Revisitando a literatura, Dayrell, acentua que o jovem é um sujeito ativo que age no e sobre o mundo e que se produz ao mesmo tempo em que é produzido, sendo importante considerar a relação que o estudante estabelece com a escola e com o saber. Ainda de acordo com o autor, "A juventude constitui um momento determinado, mas não se reduz a uma passagem; ela assume uma importância em si mesma". (DAYRELL, 2003, p. 42). As passagens que em certos contextos sociais ocorriam marcando a transição das etapas da vida, na particularidade histórica das sociedades capitalistas tem se tornado cada vez mais sutil. 
Pensamos nessa reflexão que é fundamental romper com concepções estereotipadas, as de que "o jovem não é um pré-adulto. Pensar assim é destituí-lo de sua identidade no presente em função da imagem que projetamos para ele no futuro". (DAYRELL E CARRANO,2014, p. 106). A juventude é etapa da vida social e seus significados de ser jovem ultrapassam os aspectos biológicos e psicológicos. Ser jovem oscila de acordo com as situações em que estão inseridos. Nesse sentido, ser jovem, "é também uma construção simbólica inscrita nas práticas sociais". (SPÓSITO, 2009, p. 10). Os contextos culturais são elementos fundamentais na forma como os jovens constroem sua identidade e se reconhecem no outro, estabelecendo também sua identidade coletiva. Os aspectos sociais e culturais são essenciais em se tratando dos jovens e não se separa dos processos estruturantes da vida social.

Se fizermos uma análise da proposta de educação para os jovens com deficiência no ensino médio, a LDBEN 9.394/96, é relevante assinalar que o Ensino Médio é a etapa final da escolarização básica, que comporta a Educação Infantil, o Ensino Fundamental e Ensino Médio. (BRASIL, 1996). Cumpre-nos acentuar que o Ensino Médio é etapa obrigatória de educação que vem sofrendo alterações em função de demandas econômicas e sociais contribuindo para que sejam múltiplas as necessidades postas a essa etapa de escolarização.

Nossas críticas se pauta na tese de que o Ensino Médio é a última etapa da educação básica e não vemos grandes investimentos públicos nem na ampliação dessa estrutura, nem na formação de professores que atuam nessa etapa intermediária, em especial, quando nos referimos a inclusão escolar dos jovens estudantes com deficiência que estão matriculados. A indagação que não quer calar é: por que apenas os discursos estão voltados para a inclusão no ensino fundamental e superior? Não sabemos as causas, nem ao menos as razões, pelas quais a inclusão no Ensino Médio ainda é pouco debatida junto aos órgãos governamentais nas três esferas do poder público. Ao que nos parecem, atualmente, a produção acadêmica tem seus estudos mais voltados para a inclusão no Ensino Fundamental e para o Ensino Superior. Diante do exposto, levanta-se aqui uma indagação: por que estudiosos desta temática, teóricos da educação e até mesmo os administradores públicos estão discutindo menos o Ensino Médio nas diversas instâncias do poder político.

No que concerne o Ensino Médio, a reflexão sobre o mesmo se dê pautada na análise do sujeito jovem, uma vez que a escola deva ser repensada para responder aos desafios que a juventude traz. Nesse sentido, é importante refletir a respeito da condição juvenil dos estudantes do Ensino Médio. Não se pode compreender o Ensino Médio unicamente como etapa final da educação básica ou falsamente como intermédio para acesso ao Ensino Superior e simplificar o caráter formativo dessa etapa da escolarização em um momento essencial de consolidação da formação humana, ética e política. (DAYRELL ECARRANO, 2014).

No Brasil, estamos vivenciando nosso segundo Plano Nacional de Educação, o primeiro tramitou por três anos no Congresso Nacional sancionado na Lei Federal $n^{\circ} .10 .172$, de 9 de janeiro de 2001, estabelecendo duzentos e noventa e cinco (295) metas para educação até o ano 2011. (BRASIL, 2001). O segundo Plano Nacional de Educação, sancionado na Lei $n^{\circ} 13.005 \mathrm{e}$ aprovado em 25 de junho de 2014 estabelece vinte (20) metas para a educação até 2024. (BRASIL, 2014).

Um Plano Nacional de Educação de certa forma sintetiza o que se almeja com a educação no país, ele orienta ação de todos os envolvidos nesse processo, por isso os Estados e os Municí- 
pios também elaboram seus respectivos planos em articulação com o que estabelece o nacional. Esse processo é permeado por negociações e encontros da sociedade civil com o Estado. É uma tentativa de se estabelecer políticas e ações que não terminem com o fim de um determinado governo, ou seja, a constituição de um Plano Nacional de Educação deve ser pensada como uma política de Estado que não se esgota no fim de uma gestão.

A quantidade de metas do primeiro PNE dentre outros fatores dificultaram sua aplicação e acompanhamento. Na busca de ser mais exequível, o segundo Plano Nacional de Educação aprovado em 2014, centra-se em vinte metas das quais destacamos duas que diretamente estão relacionadas com nosso objeto de reflexão, são as Metas 3 e 4.

A Meta 3 prevê: "Universalizar, até 2016, o atendimento escolar para toda a população de 15 a 17 anos e elevar, até o final do período de vigência deste PNE, a taxa líquida de matrículas no ensino médio para 85\%". (BRASIL, 2014). Acompanha essa meta quatorze estratégias. Vejamos algumas delas:

[...] 3.8) estruturar e fortalecer o acompanhamento e o monitoramento do acesso e da permanência dos e das jovens beneficiários (as) de programas de transferência de renda, no ensino médio $[\ldots]$

3.11) redimensionar a oferta de ensino médio nos turnos diurno e noturno, bem como a distribuição territorial das escolas de ensino médio, de forma a atender a toda a demanda, de acordo com as necessidades específicas dos (as) alunos (as);

3.12) desenvolver formas alternativas de oferta do ensino médio, garantida a qualidade, para atender aos filhos e filhas de profissionais que se dedicam a atividades de caráter itinerante;

3.14) estimular a participação dos adolescentes nos cursos das áreas tecnológicas e científicas (BRASIL, 2014,).

Historicamente, o jovem tem sido colocado nas políticas que lhes são destinadas em lugar genérico de tratamento, sendo tratados ora como aluno, ora como estudante, o que tem contribuído de certa forma para a negação do ser jovem. A análise dessas estratégias evidencia certo distanciamento do que vem sendo produzido no campo acadêmico sobre o ser jovem e sua condição de juventude. O Plano Nacional de Educação, de certa forma sintetiza o que se almeja com o Ensino Médio. Nele, encontramos ausência ao sujeito jovem mesmo tendo no Brasil de certa forma estudos sobre juventude e a escola de forma a possibilitar novas articulações sobre essas duas temáticas. A escola e os trabalhadores que nela atuam devem conhecer os jovens que frequentam o ensino médio refletindo sobre como eles edificam o seu modo de ser e constroem sua identidade individual e coletiva.

A Meta 4 prevê: "Universalizar, para a população de quatro a 17 anos, o atendimento escolar aos estudantes com deficiência, transtornos globais do desenvolvimento e altas habilidades ou superdotação na rede regular de ensino". (BRASIL, 2014). A meta é a de colocar $100 \%$ dos estudantes até os 17 anos no Ensino Médio, o que nos parece um tanto quanto ousada.

Se fizermos uma análise do Censo da educação é notório assinalar que apenas 7.833.218 dos jovens estavam matriculados no Ensino Médio. Isso nos revela que apenas 22,8\% estão adentrando no Ensino Médio. (BRASIL/INEP, 2018). O problema crucial a ser enfatizado é que a faixa etária desses estudantes é de 15 a 24 anos, longe de alcançar a Meta 4, proposta pelo novo Plano Nacional de Educação. Nada mais que, há quatro anos os dados do Censo/Inep eram assustadores se levarmos em consideração que a Meta 4 quer alcançar 100\% dos jovens 
com até 17 anos no Ensino Médio. Essa ousada Meta objetiva cumprir este percentual até o ano de 2024.

Estudos publicados recentemente, constata-se de que:

[...] que pouco mais da metade dos jovens que tem direito ao ensino médio o estão frequentando e destes, apenas $25 \%$ na idade adequada. Os demais o frequentam com idade defasada, resultado de repetições e interrupções. Mais de $50 \%$ fazem o ensino médio no turno noturno e boa parte no PROEJA. (FRIGOTTO, 2009, p. 26).

Os dados são assustadores, se pensarmos que não falta nenhuma década mais para que a Meta 4 cumpra com essa alarmante defasagem, ou seja, aproximadamente $75 \%$ dos jovens não frequentam o Ensino Médio na faixa etária proposta, e 50\% estão no ensino noturno, obviamente por uma causa crucial, seguramente são jovens trabalhadores. Não basta apenas universalizar o Ensino Médio para os jovens. Não basta também colocar $100 \%$ dos jovens até 17 anos no Ensino Médio até 2024. O maior desafio do poder público é o de garantir, além do acesso, a permanência, a progressão e a conclusão na idade adequada. Nesse sentido, é de fundamental importância ressaltar a veemente necessidade de ações e programas governamentais que efetivamente priorizem a universalização do Ensino Médio com qualidade.

Outro grande desafio a ser enfrentado pelo poder público nas três esferas, são os estudantes retidos no Ensino Fundamental e que de lá nunca saíram, os que evadiram da sala de aula por motivos diversos, aqueles que por alguma situação social ou acadêmica foram reprovados e, por fim, aqueles estudantes que nunca frequentaram a escola, não têm registro de matrículas e, portanto, não compõem as estatísticas.

A presença tardia do Estado frente à educação pública tem provocado uma dualidade perversa no ensino médio, pois se de um lado registra-se uma considerável parcela dos jovens nos cursos propedêuticos, obviamente originados das classes mais favorecidas economicamente, por outro, deve considerar que outra grande parcela dos jovens estudantes que ingressam no ensino médio, vão para os cursos técnicos ou profissionalizantes. Em nosso entendimento a formação construída no Ensino Médio deve possibilitar a escolha do estudante jovem em seguir para o ensino superior ou ter sua formação profissionalizante como assim o desejar, a escola deve lhe possibilitar as condições para escolha.

Pensamos ser necessário acentuar que a universalização do ensino dos 4 aos 17 anos está garantido desde 2009 na Emenda Constitucional $n^{\circ}$ 59, que institui a obrigatoriedade do Ensino Médio, colocando-o como etapa obrigatória a ser devidamente alcançada nas três esferas do poder público. (BRASIL, 2009). Obviamente, essa Emenda representa um avanço no que concerne à inclusão escolar dos estudantes com e sem deficiência no Ensino Médio até os 17 anos, porém, comete um retrocesso ao limitar a idade. O problema é se o Estado brasileiro, carcomido por um falso discurso político, vai efetivamente cumprir com a Meta 4, que é a de colocar até 2024 todos os estudantes na sala de aula do ensino regular.

Em se tratando da inclusão escolar dos jovens estudantes com deficiência, essa meta não se configura em uma tarefa fácil, dado o descaso que ainda se verifica no sistema educacional brasileiro, pois ainda há cursos de licenciaturas voltados à formação de professores que não contempla em sua grade curricular disciplinas que enfatizam a inclusão das pessoas com deficiência na educação básica. Neste sentido, "a inclusão implica em uma reforma radical nas escolas em termos, principalmente, de currículos, avaliação, agrupamentos dos estudantes nas atividades 
coletivas em sala de aula". (ZARDO, 2012, p. 75). Essa proposta se baseia em valores cuja meta é fazer com que todos se sintam bem-vindos a diversidade, respeitando diferentes gêneros, raça, linguagem, nível social, grau de educação e deficiência em uma perspectiva inclusiva.

Como vimos, não é recente o discurso sobre o direito à educação para todos os cidadãos. Obviamente, não é por força das benesses políticas que esses direitos vêm gradativamente se efetivando. Frente essa assertiva, acentuamos que "não foi por causa dos políticos que as políticas educacionais mudaram, não foi porque os políticos esperaram os pesquisadores dizerem a palavra certa, mas foi porque a sociedade exigiu mudanças". (MITTLER, 2003, p. 15). Diante desse pressuposto, cumpre-nos ressaltar que em relação à educação, essas mudanças não vêm espontaneamente, é preciso que possamos nos organizar no sentido de fazer valer nossos direitos sociais.

A inclusão dos estudantes com deficiência no Ensino Médio, necessariamente, deverá estar ladeada de alguns princípios que visam à promoção da inclusão desses sujeitos sociais na escola comum. No que concerne ao Atendimento Educacional Especializado (AEE), são princípios suleadores do artigo 59 da LDBEN 9394/96, que os sistemas de ensino devem assegurar aos estudantes com deficiência adequação curricular, métodos diferenciados, recursos didáticos adaptados e procedimentos acessíveis a efetivação de sua inclusão na escola comum, em todas as etapas e modalidades. (BRASIL, 1996).

O processo de inclusão escolar dos jovens com deficiência em todas as etapas e modalidades está ladeado de alguns obstáculos pedagógicos, ou para ser mais racional, de diversas ingerências de professores que não aceitam flexibilizar seu planejamento escolar, quando em sua sala, estudantes com deficiência se fazem presente. Isso se verifica, na medida em que alguns professores não promovem a adequação no currículo, não respeitam os diferentes ritmos de aprendizagem dos estudantes com deficiência e nem fazem reformulação nos diversos processos avaliativos.

Ao anunciar que até 2024,100\% dos jovens até 17 anos, com ou sem deficiência, deverão ingressar no Ensino Médio, é preciso resgatar a Lei $\mathrm{n}^{\circ} 10.172$, de 09 de janeiro de 2001, que aprovou o PNE (2001-2011), as diretrizes deste plano asseguram a educação e as alternativas de serviços especializados aos estudantes com deficiência na escola comum. Entre esses direitos, destacam a importância da intervenção educacional desde a infância até a fase adulta; a articulação de ações entre a educação, a saúde e a assistência social; a formação de profissionais habilitados para a oferta de Atendimento Educacional Especializado; a organização de escolas especiais filantrópicas em parcerias com instituições regulares de modo a atender os estudantes com deficiência que estão matriculados na rede regular de ensino. (BRASIL, 2001).

O Atendimento Educacional Especializado aos estudantes com deficiência, altas habilidades e superdotação é garantido desde a educação infantil ao ensino superior. O documento: A política nacional de educação especial na perspectiva da educação inclusiva foi publicada em 07 de janeiro de 2008. Cumpre-nos assinalar que é objetivo dessa política, assegurar a inclusão escolar de estudantes com deficiência, transtornos globais do desenvolvimento, altas habilidades e superdotação, orientando os sistemas de ensino visando garantir acesso ao ensino regular, com participação, aprendizagem e continuidade nos níveis mais elevados do ensino, bem como a oferta do Atendimento Educacional Especializado aos estudantes com deficiência, além do investimento na formação de professores e aos demais profissionais que atuam na educação especial. (BRASIL, 2008). 
A organização do Atendimento Educacional Especializado é garantida pela Resolução $\mathrm{CNE} / \mathrm{CEB} \mathrm{n}^{\circ} 4$, que institui as diretrizes operacionais do atendimento educacional especializado na educação básica na modalidade da educação especial. Essa resolução garante através do artigo $1^{\circ}$, os sistemas de ensino devem matricular os estudantes com deficiência, transtornos globais do desenvolvimento, altas habilidades superdotação nas classes comuns do ensino regular e no Atendimento Educacional Especializado - AEE, ofertados em salas de recursos multifuncionais, centro especializados da rede pública, escolas convencionais e instituições filantrópicas. De acordo com o artigo 2 desta Lei, o AEE tem como função: "complementar ou suplementar a formação do aluno por meio da disponibilização de serviços, de recursos de acessibilidade e estratégias que elimine as barreiras para sua plena participação na sociedade e desenvolvimento de sua aprendizagem". (BRASIL, 2009). A menção supracitada não basta, afinal, precisamos desenvolver políticas públicas de inclusão que possibilitem não apenas a matrícula do estudante com deficiência na escola comum, mas também seu sucesso e permanência.

O foco dispensado à acessibilidade, a ruptura das barreiras físicas, arquitetônicas e atitudinais só podem ser garantidos por meio de políticas públicas que permitem o ir e vir das pessoas com deficiência nos diferentes espaços sociais. Neste contexto, insere-se o Atendimento Educacional Especializado que tem como meta apoiar no contra turno do ensino comum os estudantes com deficiência que frequentam a escola regular.

O suporte aos estudantes com deficiência matriculados na escola comum é um direito garantido na legislação. Neste aspecto, é necessário assinalar que até o ano de 2010 foram criadas 24.3012 salas de recursos multifuncionais cuja meta era atender no contra turno os estudantes que frequentam a escola comum. Cumpre-nos acentuar que essas salas são equipadas com mobiliários, materiais didáticos, recursos pedagógicos e recursos de acessibilidade.

A problemática recorrente que pode ser evidenciada acerca das salas de recursos multifuncionais, é que essas estão sendo a válvula de escape para maquiar o processo de inclusão escolar das pessoas com deficiência. Na nossa concepção, não se faz inclusão apenas investindo no Atendimento Educacional Especializado. Este não garante a efetiva inclusão. Pensamos ser necessário investir maciçamente na formação inicial e continuada dos professores no ensino especial e no ensino comum, pois sozinhos, isolados e sem a possibilidade de realizar parcerias, a inclusão será uma mera utopia.

À luz da literatura, a Resolução n ${ }^{\circ}$ 04, do Conselho Nacional de Educação prescreve que ao Atendimento Educacional Especializado, cabe:

I - Identificar, elaborar, produzir e organizar serviços, recursos pedagógicos, de acessibilidade e estratégias considerando as necessidades específicas dos alunos público-alvo da Educação Especial;

II - Elaborar e executar plano de Atendimento Educacional Especializado, avaliando a funcionalidade e a aplicabilidade dos recursos pedagógicos e de acessibilidade;

III - organizar o tipo e o número de atendimentos aos alunos na sala de recursos multifuncionais;

IV - Acompanhar a funcionalidade e a aplicabilidade dos recursos pedagógicos e de acessibilidade na sala de aula comum do ensino regular, bem como em outros ambientes da escola;

V - Estabelecer parcerias com as áreas intersetoriais na elaboração de estratégias e na disponibilização de recursos de acessibilidade; 
VI - Orientar professores e famílias sobre os recursos pedagógicos e de acessibilidade utilizados pelo aluno;

VII - ensinar e usar a tecnologia assistiva de forma a ampliar habilidades funcionais dos alunos, promovendo autonomia e participação;

VIII - estabelecer articulação com os professores da sala de aula comum, visando à disponibilização dos serviços, dos recursos pedagógicos e de acessibilidade e das estratégias que promovem a participação dos alunos nas atividades escolares. (BRASIL, 2009).

Todas essas estratégias só terão efeitos práticos se a escola disponibilizar esses recursos aos estudantes. Se os professores do ensino comum e do ensino especial conseguirem trabalhar de forma colaborativa e se os professores forem qualificados continuamente.

Leis, Decretos, Legislações, Conferências e Resoluções não são suficientes para garantir a efetivação desses serviços. Pensamos nessas reflexões que o poder público precisa imediatamente fazer valer esses direitos. No que concerne à inclusão dos jovens estudantes no Ensino Médio, a tarefa é árdua, a missão profissional é enorme e o compromisso político dos nossos administradores é profundamente necessário para que até 2024 , todos os jovens estudantes com deficiência possam estar incluídos na escola comum até os 17 anos.

Nossas reflexões acerca do AEE são as seguintes: parte dos municípios brasileiros, em larga escala, não estão preparados para oferecer suportes pedagógicos, recursos didáticos e tecnologia assistiva que possibilitem a efetiva inclusão dos jovens com deficiência na escola comum, principalmente, quando nos referimos as metas propostas pelo Plano Nacional de Educação, que é de colocar na escola comum 100\% dos estudantes até 17 anos de idade no Ensino Médio.

Outra questão que refutamos ser crucial no que concerne às metas propostas pelo Plano Nacional de Educação, se restringe ao campo da formação inicial e continuada dos professores nas licenciaturas, pois ainda há cursos de formação que não contemplam em suas grades disciplinas sobre educação especial na perspectiva da educação inclusiva e temáticas sobre os sujeitos de Ensino Médio.

Não há, no atual sistema educacional brasileiro, na nossa concepção, nenhuma rede de ensino especial que sustenta estudantes com deficiência incluídos na escola comum, sem haver o Atendimento Educacional Especializado. Partindo dessa premissa, refutamos como salutar a oferta de recursos de acessibilidade, tecnologia assistiva e serviços de profissionais habilitados nas diferentes áreas e especialidades, de modo a garantir não apenas o ingresso dos estudantes com deficiência em todas as etapas e modalidade da educação especial, mas também, seu sucesso e permanência na escola comum.

No atual sistema educacional brasileiro, carcomido por um discurso de "educação para todos"; "ordem e progresso"; "Brasil acima de tudo"; "pátria educadora"; enfim, de mais recursos para a educação, pensamos que a execução da Meta 4, que visa universalizar o atendimento de 4 a 17 anos para os estudantes com deficiência, transtornos globais do desenvolvimento, altas habilidades e superdotação na rede regular de ensino, é uma falácia no atual contexto educacional, considerando que em nossa opinião, essa meta nos parece distante da realidade brasileira. Incluir no ensino médio $100 \%$ dos jovens até 17 anos não se constitui em uma tarefa fácil.

No que concerne às matrículas de jovens estudantes com deficiência no Ensino Médio, isto é, sem considerar a faixa etária proposta pelo Plano Nacional de Educação que é até 17 anos, dados do INEP revelam que foram matriculados no Ensino Médio 7.833.218 estudantes, 
sendo 23.272 matrículas de pessoas com deficiência. Esses dados nos revelam que ainda é um tanto quanto insignificante o baixo número de jovens com deficiência que frequentam o Ensino Médio, ou seja, apenas 0,29\%. (BRASIL/INEP, 2016).

As condições que a escola se encontra atualmente, a falta de recursos financeiros que possa suprir as necessidades pedagógicas, a necessidade de adaptar currículos e propostas educativas à nova realidade, somada a falta de investimento na formação inicial e continuada, nos faz pensar que a Meta 4, que se refere à inclusão dos estudantes com deficiência, terá muitas dificuldades para se efetivar até o ano de 2024. Fazemos essa afirmação porque, hoje, a escola brasileira está ladeada de grandes desafios, pois estão adentrando nessa instituição de ensino jovens estudantes com deficiência, transtornos globais do desenvolvimento, altas habilidades e superdotação que não têm suporte de professores especialistas. A realidade vivenciada no ensino comum, é de que ainda há professores que não tiveram em sua formação disciplinas sobre educação especial e temáticas relativas às questões da juventude, pior que isso, nunca fizeram um curso de formação de curta duração para atender alunos surdos, cegos, paralisado cerebral, autistas dentre outros.

\section{A inclusão dos jovens estudantes com deficiência no Ensino Médio em Goí́s: o CASO de JATAí}

O município de Jataí pertence à Mesorregião Sul Goiano e Microrregião do Sudoeste de Goiás. Possui segundo dados do IBGE, população estimada em 2018, de 100.825, habitantes. Em 2010 a população residente era de 92.006 pessoas. O município conta com a oferta do Ensino Médio público e privado, sendo sete instituições estaduais, seis privadas e uma federal, totalizando em 2014, quando da aprovação do novo Plano Nacional de Educação, 4.927 estudantes matriculados. Dados do censo escolar revelam que todas as escolas que ofertam ensino médio estão localizadas na zona urbana.

De acordo com análise das metas propostas pelo Plano Nacional de Educação no município investigado, levanta-se aqui algumas indagações: As redes de ensino estão preparadas para que até 2024 os alunos com 17 anos possam concluir o Ensino Médio? Os sistemas inclusivos idealizados pelo MEC vão dar conta de elaborar e executar políticas públicas de inclusão que permitem que esses jovens estejam aptos a concluir o Ensino Médio até os anos previstos? Será que o município lócus da nossa investigação está preparado para incluir $100 \%$ dos jovens com deficiência até o ano de 2024, nas escolas comuns? O Atendimento Educacional Especializado que temos atualmente instalado nesse município, vai conseguir oferecer suporte pedagógico, recursos didáticos e formação de profissionais qualificados que atenda esses jovens no contra turno da escola regular, oferecendo-lhes suportes necessários à sua efetiva inclusão até 2024 ?

A inclusão escolar de estudantes com deficiência no Estado de Goiás representa um significante número para a Região Centro-Oeste. Dados do senso educacional em Goiás demonstram que "há no Estado 1.119 escolas estaduais, 10 escolas especiais e 20 instituições especializadas conveniadas". (ZARDO, 2012, p. 197). No que concerne ao atendimento educacional especializado, a autora menciona que as escolas especiais e as instituições especializadas se sentem na obrigação de oferecer o AEE no contra turno, porque são dependentes financeiramente dos recursos disponibilizados pela secretaria, em relação a manutenção e pagamento dos profissionais que atuam nessas instituições especializadas ou mesmo nas escolas conveniadas. 
No Estado de Goiás, um dos desafios encontrados para a permanência dos estudantes com deficiência na escola comum, é o grande número de estudantes matriculados por sala (40 jovens). O problema identificado na rede estadual é que com 40 estudantes nas salas e sem um professor auxiliar, não é possível fazer acontecer uma verdadeira inclusão, até porque nenhum docente consegue acompanhar o rendimento individual dos estudantes considerados normais, imagine daqueles com deficiência matriculados.

Ao analisar os dados que revelam a inclusão no Estado de Goiás, apontamos para os professores alguns desafios a serem transpostos como: A permanência desses estudantes em sala de aula; O grande número de estudantes matriculados; A falta de professor auxiliar em sala de aula; A quase inexistência de uma rede de apoio à inclusão; A forma como o currículo está organizado, considerando que não há adaptação/adequação desse para atender os alunos com deficiência, dentre outros. (ZARDO, 2012).

Outro fenômeno que identificamos nos documentos oficiais que propõem a implementação do projeto de educação em Goiás, é a falta de colaboração entre governo federal, estadual e municipal. Isso fere a nosso ver, o princípio constitucional proposto pela LDBEN 9394/96 que orienta nas três esferas que haja o regime de colaboração no sentido de ofertar educação básica nas diferentes etapas e modalidades de ensino. (BRASIL, 1996).

Uma constatação que nos deixou surpreso sobre a inclusão dos jovens estudantes no Ensino Médio no Estado de Goiás, diz respeito à inclusão dos surdos nas escolas comuns. Pesquisas revelam que a inclusão dos estudantes surdos se destaca porque há um maior número de profissionais habilitados na língua brasileira de sinais (Libras). Ainda de acordo com as pesquisas, as escolas estão mais bem preparadas no sentido de utilizar melhor os recursos disponíveis voltados à inclusão dos surdos na educação básica, em especial no Ensino Médio. (ZARDO, 2012).

No intuito de fazer uma análise acerca da inclusão escolar dos jovens com deficiência matriculados no município, lócus da nossa pesquisa, lançamos mão dos seguintes dados obtidos junto à Secretaria Municipal de Educação. No ano de 2015, portanto, um ano após a publicação do PNE, foram matriculados no Ensino Médio 4.927, alunos. Desse total, apenas 33 alunos são da educação especial. Considerando o índice percentual, isso equivale a $0,6 \%$ de todas as matrículas no Ensino Médio. Os dados nos impressionam, quando observamos que mesmo com os avanços da informática, das tecnologias assistivas e com a facilidade de acesso a comunicação virtual, o índice de matrículas cresceu pouco em relação ao ano anterior, ou seja, as matriculas cresceram na rede regular de ensino para 4.946, alunos, cujo percentual no ensino especial chegou apenas $0,72 \%$ de alunos matriculados, isso quer dizer que apenas 36 alunos são da educação especial.

Ao chegar em 2019, cinco anos após o PNE ser aprovado, os dados também não são animadores, considerando que esse número caiu para 4.540 alunos matriculados no Ensino Médio, apenas 32 são da educação especial, ou seja, 0,70\% das matrículas são de alunos com deficiência.

Finalmente, estamos em 2020 e lá se foram cinco anos. Se observarmos que a Meta 4, prevê que o sistema educacional deverá matricular 100\% dos alunos com deficiência, transtornos globais do desenvolvimento, altas habilidades e superdotação no Ensino Médio dos 15 aos 17 anos até 2024, as perspectivas não são animadoras, pois das 23.596 matrículas realizadas no município de Jataí, nos últimos cinco anos, apenas 163 são alunos da educação especial que 
estão frequentando a escola comum. Os dados nos revelam que deste contingente apenas 3,37\% das matrículas se originaram da educação especial. Esse número representa um índice muito baixo em relação às propostas que a Meta 4 objetiva alcançar até o ano de 2024, ano limite para que as 20 metas do PNE possam ser realizadas.

No sistema educacional que ora se desenha a inclusão escolar dos estudantes com deficiência até os 17 anos, proposta pela meta 4, nos parece temerosa, visto que as pessoas com deficiência, transtornos globais do desenvolvimento, altas habilidades e superdotação requer tratamento diferenciado, no que concerne sua plena participação no espaço escolar.

As especificidades das pessoas com deficiência, a necessidade de adaptar à escola, bem como adequar o currículo, a aquisição de mobiliários e equipamentos, adoção de tecnologia assistiva, a organização de espaços pedagógicos especializados por exemplo, a AEE, a parceria entre professores do ensino comum e ensino especial, o maciço investimento na formação inicial e continuada, dentre outros são desafios que o poder público nas três esferas terá de enfrentar para colocar em prática a Meta 4.

Ao propor que o Plano Nacional de Educação por meio da Meta 4, inclua todos os estudantes com deficiência no Ensino Médio até os 17 anos, o governo não pode esquecer que os jovens com deficiência tem limitações, no que concerne adoção de recursos didáticos, métodos de ensino diferenciados, recursos pedagógicos adaptados, processos avaliativos não comparativos aos demais estudantes, suportes técnicos acessíveis, recursos humanos preparados, professores habilitados nas diferentes deficiência, transtornos globais do desenvolvimento, altas habilidades e superdotação.

É um grande equívoco a crença de que os estudantes com deficiência aprendem no mesmo ritmo, da mesma forma, do mesmo jeito, usando os mesmos mecanismos, recursos e procedimentos. O fardo pesa em nossos ombros quando nos vemos diante das limitações atinentes à deficiência que somos acometidos, pois ser diferente em uma sociedade capitalista é demonstrar fragilidade, sofrer preconceitos, ser vistos como incapaz diante do contexto que exclui, discrimina e estigmatiza pelo rótulo da desigualdade.

Análise dos dados do censo escolar do município de Jataí de 2016 permite inferir que a taxa de abandono é considerável, principalmente no primeiro ano do Ensino Médio, chegando a alguns casos há $16,9 \%$. A taxa de reprovação também para o primeiro ano é ainda mais assustadora, chegando a certos casos a $38,6 \%$.

Conhecendo a realidade educacional do município, lócus da nossa investigação, pensamos que as metas propostas pelo PME até 2024, não serão alcançadas, pois garantir a inclusão escolar de jovens com deficiência até 17 anos na escola comum, será preciso uma total reformulação nas políticas educacionais deste município, até porque, não se faz inclusão apenas decretando projetos, elaborando metas imediatistas e publicidades eufemistas. A inclusão escolar requer muito mais. Requer investimento em médio prazo, investimento este em equipamentos, recursos tecnológicos, tecnologias assistivas e principalmente na formação inicial e continuada dos professores que vão atuar na sala de aula comum, quando nessa se fizer presente estudantes com deficiência.

O município, lócus da nossa investigação, não demonstra preparo para alcançar os objetivos propostos pela Meta 4, que visa incluir todos os estudantes com deficiência até 17 anos no 
Ensino Médio. Soma-se a essa dificuldade, outros fatores que refutamos ser empecilho a inclusão desses jovens com deficiência, a saber:

a) o acesso a escolarização a essas pessoas ainda é muito restrito principalmente no que concerne a inclusão no Ensino Médio;

b) a cultura social vigente estigmatiza os jovens estudantes com deficiência como um ser incapaz, no sentido de adquirir o conhecimento científico e sua inserção no mercado de trabalho;

c) grande parte dos jovens com deficiência pertencem às camadas mais pobres, carentes de benefícios e programas sociais de renda do governo federal;

d) finalmente, em municípios como o que estamos investigando, há poucas escolas que oferecem Atendimento Educacional Especializado, bem como matrículas para jovens com deficiência que querem frequentar o Ensino Médio.

Outro problema identificado nesse estudo, em especial no município onde realizamos a investigação, é a incompreensão dos professores quando confundem as salas de recursos multifuncionais com salas de reforço escolar. Esse espaço deve ser constituído como um conjunto de procedimentos pedagógicos alternativos cuja intenção é mediar o saber previamente trabalhado na sala regular. Entendemos as salas de recursos multifuncionais como um espaço pedagógico, no qual, há um conjunto de ferramentas as quais os professores lançam mão para atuarem de forma colaborativa, envolvendo o ensino comum e o ensino especial.

Na nossa avaliação, não há inclusão, seja no Ensino Médio ou em qualquer etapa e modalidade do ensino especial, voltado às pessoas com deficiência se as escolas não contarem em seu quadro, com serviços de profissionais especializados como: intérpretes de Libras, professores de Libras, instrutores de Libras, transcritores e revisores em Braille, profissionais de apoio, cuidadores, monitores, guia-intérprete, dentre outros. A problemática - em relação ao município lócus da nossa investigação, é que o mesmo não oferece no campo, salas de recursos multifuncionais, formação inicial e continuada dos professores e o Atendimento Educacional Especializado. Frente ao exposto, pensamos que até 2024, ano limite para que essa meta seja alcançada, não acreditamos no cumprimento dessa, pois até o momento, muitos jovens com deficiência, indígenas, quilombolas que residem no campo estarão fora da escola, sem condição de acesso ao Ensino Médio.

Aos olhos da Lei 13.005, de 25 de junho de 2014, na Meta 4 em uma de suas atribuições prevê que: o poder público deve incentivar a inclusão nos cursos de licenciatura e nos demais cursos de formação para profissionais da educação, inclusive em nível de pós-graduação, observado o disposto no caput do art.207 da Constituição Federal, dos referenciais teóricos, das teorias de aprendizagem e dos processos de ensino-aprendizagem relacionados ao atendimento educacional de alunos com deficiência, transtornos globais do desenvolvimento, altas habilidades e superdotação (BRASIL, 2014).

$\mathrm{Na}$ nossa concepção, essa atribuição nos parece longe de se efetivar no município que estamos investigando, até porque, os professores que atuam no Ensino Fundamental e Médio não têm o cumprimento do plano de carreira, bolsa remunerada para se qualificar e direito ao afastamento para ingressar na pós-graduação em nível de mestrado e doutorado. Desse modo, sem investir na formação continuada dos docentes que atuam com populações especiais, sem as 
salas de recursos que dão suporte aos professores do ensino comum, seguramente, a juventude com deficiência irá concluir o ensino médio na idade certa, conforme propõe o novo PNE.

Considerando a inclusão dos jovens até os 17 anos que estão adentrando no Ensino Médio, não temos dúvidas em afirmar que há especificidades a serem analisadas no que concerne ao acesso e permanência desses na escola. Ao identificar na Meta 3, em especial no item 3.7, o objetivo é: "fomentar a expansão das matrículas gratuitas de Ensino Médio integrado à educação profissional, observando as peculiaridades das populações do campo, das comunidades indígenas e quilombolas e das pessoas com deficiência". Se levarmos em consideração as dificuldades que há no município investigado, esse objetivo está longe de se efetivar, pois não há escolas que ofereça ensino profissionalizante no campo que atenda essas pessoas no Ensino Médio em seu local de origem.

A constatação de que no município lócus da nossa investigação, 14,6\% dos alunos com deficiência, transtornos globais do desenvolvimento, altas habilidades e superdotação até os 17 anos, não frequentam a escola nos assusta, mesmo porque conforme prevê a Meta 4 do Plano Nacional de Educação, até 2024 todos os jovens que estão nesta faixa etária devem estar regularmente matriculados no Ensino Médio.

Ao nos referirmos a inclusão escolar das pessoas com deficiência, transtornos globais do desenvolvimento, altas habilidades e superdotação, nossas expectativas se elevam, principalmente quando nos referimos a esses novos sujeitos que estão adentrando na educação especial na perspectiva da educação inclusiva.

A análise acerca da Meta 4 do PNE, o qual prescreve que até o ano de 2024 todos os alunos de 15 aos 17 anos, com deficiência, devem ser matriculados no Ensino Médio. Diante dessa assertiva, é possível fazer algumas reflexões:

a) No município em que atuamos não há salas de recursos multifuncionais suficientes para o atendimento educacional especializado no contra turno do ensino comum, para esses novos sujeitos que estão adentrando na escola nos últimos anos;

b) Não há neste município, lócus da nossa investigação, políticas públicas de incentivo voltadas à formação continuada dos docentes que atuam na educação especial em uma perspectiva inclusiva.

\section{Notas (In)ConClusivas}

Nossas considerações não são finais, nem ao menos conclusivas, pois sabemos que o Estado brasileiro tem muito a fazer para que a educação se torne efetivamente um direito social. Neste sentido, cumpre-nos assinalar que ao nos referirmos ao Estado, precisa se convencer de que a efetivação deste direito é uma meta que precisa ser alcançada. Assim, a inclusão dos estudantes com deficiência no Ensino Médio até os 17 anos, é um dever a ser cumprido, cabendo ao Estado implementar políticas públicas eficientes, eficazes e relevantes a fim de poder alcançar essa importante meta.

Após análise da Lei n ${ }^{\circ} 13.005$, aprovada em 25 de junho de 2014, sucinta algumas dúvidas, a saber: a ausência de políticas públicas do Estado com caráter transformador será capaz de superar as desigualdades que ainda existem no sistema público de educação? A exclusão social e as injustiças que ainda se encontram presentes no território brasileiro, pois há município no país 
que não conta com escolas para incluir estudantes do ensino fundamental, imagine quando se refere à inclusão dos jovens com deficiência até os 17 anos no Ensino Médio.

$\mathrm{O}$ aspecto positivo identificado em nossa análise das ações da Meta 4, é o de estimular a construção de centros multidisciplinares compostos por profissionais das variadas especialidades, cuja intenção é fazer um trabalho colaborativo envolvendo escolas regulares e escolas especiais de modo a facilitar o ingresso e permanência dos estudantes com deficiência no Ensino Médio até os 17 anos. Nesse sentido, são muitas as atribuições que a Meta 4 tem a responsabilidade de implementar até o ano de 2024.

Em nossas reflexões nos preocupa o fato de que alguns municípios brasileiros, em especial o qual investigamos, pensamos que as possibilidades são mínimas, dada as especificidades, prioridades e ação política do poder público municipal. Diante do exposto, indagamos: será que vai ser possível fomentar pesquisas que promovam o desenvolvimento de metodologias, materiais didáticos, equipamentos e recursos de tecnologia assistiva que possibilitem a promoção do ensino e da aprendizagem para todos os jovens com deficiência, altas habilidades e superdotação até os 17 anos no Ensino Médio?

O problema crucial identificado nessa reflexão diz respeito ao baixo índice de jovens com deficiência, transtornos globais do desenvolvimento, altas habilidades e superdotação incluídos no Ensino Médio até os 17 anos. A construção dos resultados identificados nessa investigação, diz respeito a uma situação educacional lógica. Os jovens com deficiência, não têm no município investigado serviços especiais, como: atendimento educacional especializado, salas de recursos multifuncionais, salas especiais, classes e/ou escolas especializadas, serviços especializados públicos ou conveniados que possam atender no contra turno do ensino comum esses alunos que estão matriculados na escola regular.

Nossa crença em uma educação libertadora, humana e humanizante, se ampara na importância do trabalho colaborativo entre professores do ensino comum e professores do ensino especial. Diante dessa assertiva, pensamos que a prática interdisciplinar envolvendo as diferentes áreas do conhecimento, muito pode contribuir para que façamos uma escola verdadeiramente inclusiva. Soma-se a essas necessidades, a crença de que não há sistema educacional inclusivo que se sustente se os jovens com deficiência, transtornos globais do desenvolvimento, altas habilidades e superdotação não têm atendimento educacional especializado, salas de recursos multifuncionais e centro de referência composto por equipe multidisciplinar especializada que atenda esses estudantes no contra turno do ensino comum.

Consideramos que na era das redes, do mundo robotizado, enfim, na era digital, a adoção das tecnologias assistivas são ferramentas da maior importância para se efetivar a inclusão escolar dos jovens com deficiência no ensino comum, em especial, quando essas estão frequentando a última etapa da educação básica. Nossas reflexões acerca da Meta 4, que prevê as matrículas dos estudantes com deficiência até os 17 anos, é que esta poderá se efetivar se o sistema municipal de educação investir em serviços especializados, profissionais habilitados nas diferentes áreas da educação especial, salas de recursos multifuncionais, dentre outros serviços.

A universalização que prevê o PNE para o Ensino Médio, deve ser promovida com a devida qualidade e articulação para a permanência desses jovens estudantes na escola principalmente para os com deficiência, ou seja, sem ignorar as necessidades dos jovens que por sua vez não são homogêneas. O PNE sozinho, isolado, não garante mudanças no Ensino Médio, é 
necessário disposição para alcançar as metas bem como condições materiais e infraestrutura que garantam a qualidade da educação.

Finalmente, nossas considerações não são conclusivas, não se configuram em receitas, nem ao menos em uma escola utópica, distante da realidade educacional brasileira. Nossas reflexões se apoiam na possibilidade de construir uma escola que seja capaz de abrigar as diferenças na e para a diversidade. Isso não é utopia, isso é possível.

\title{
NATIONAL EDUCATION PLAN: ANALYSIS OF YOUTH INCLUSION IN HIGH SCHOOL
}

\begin{abstract}
This article is a result of our reflections on the Law $n^{\circ} 13,005$ which establishes the National Education Plan (PNE), approved on June 25th 2014. In this study we've discussed the goals proposed for the inclusion of young students with disabilities in High School until 2024. Our aims in these theoretical reflections were: to analyze the Law $n^{\circ}$ 13,005 of June 25th, 2014 which establishes the National Education Plan - PNE (2014-2024), seeking to assess whether the said document gathers the conditions for a possible implementation of the goal proposed for the inclusion of young students with disabilities in High School. In this itinerary we were guided by qualitative research and document analysis. Preliminary results showed us that the challenges to implement that said goal are numerous. We consider it important to expand studies in order to monitor the implementation of PNE until 2024.
\end{abstract}

KEYWORDS: High School. Goal 4. Disabilities. Youth. Educational Policies.

\section{REFERÊNCIAS}

BRASIL. Ministério da Educação. Instituto Nacional de Estudos e Pesquisas Educacionais Anísio Teixeira (INEP). Censo Escolar. Brasília, DF: MEC/INEP, 2016. Disponível em: <http://www.inep.gov. br/>. Acesso em: 27 mar. 2020.

BRASIL. Constituição da República Federativa do Brasil de 1988. Disponível em: <http://www.planalto.gov. br/ccivil_03/constituicao/constituicao.htm>. Acesso em: 07 maio 2019.

BRASIL. Nota Técnica - SEESP/GAB/No 11/2010. Disponível em: <http://portal.mec.gov.br/index. php?option $=$ com_docman $\&$ view $=$ download $\&$ alias $=5294$-notatecnica-n112010\&category_slug $=$ maio2010-pdf\&Itemid=30192> . Acesso em: 25 maio 2019.

BRASIL. Emenda Constitucional n 59, de 11 de novembro de 2009. Disponível em: <http://www.planalto. gov.br/ccivil_03/constituicao/Emendas/Emc/emc59.htm>. Acesso em: 06 mar. 2020.

BRASIL. Lei 7.853, de 24 de outubro de 1989. Disponível em: <http://www.planalto.gov.br/ccivil_03/leis/ 17853.htm>. Acesso em: 07 nov. 2019.

BRASIL. Lei no 9.394, de 20 de dezembro de 1996. Lei de Diretrizes e Bases da Educação Nacional. Brasília, 1996. Disponível em: <http://www.planalto.gov.br/ccivil_03/leis/19394.htm>. Acesso em: 05 maio 2018.

BRASIL. Lei $n^{\circ}$ 10.172, de 09 de janeiro de 2001. Aprova o Plano Nacional de Educação e dá outras providências. Disponível em: <http://www.planalto.gov.br/ccivil_03/leis/leis_2001/110172.htm>. Acesso em: 05 mar. 2020.

BRASIL. Lei n 13.005 , de 25 de junho de 2014. Aprova o Plano Nacional de Educação - PNE e dá outras providências. Disponível em: <http://www.planalto.gov.br/ccivil_03/_Ato2011-2014/2014/Lei/ L13005.htm>. Acesso em: 09 out. 2019.

BRASIL. Secretaria de Educação Especial. Política nacional de educação especial na perspectiva da educação inclusiva. Brasília: MEC, 2008. Disponível em: <http://portal.mec.gov.br/arquivos/pdf/ politicaeducespecial.pdf $>$. Acesso em: 13 nov. 2019.

BRASIL. Resolução CNE/CEB $n^{\circ} 4$, de 02 de outubro de 2009. Institui Diretrizes Operacionais para o Atendimento Educacional Especializado na Educação Básica, modalidade Educação Especial. Disponível em: <http://peei.mec.gov.br/arquivos/Resol_4_2009_CNE_CEB.pdf>. Acesso em: 08 mar. 2020. 
DAYRELL, Juarez. O jovem como sujeito social. Revista Brasileira de Educação, Campinas, n. 24, set./dez. 2003. Disponível em: <http://www.scielo.br/pdf/rbedu/n24/n24a04.pdf>. Acesso em: 15 jan. 2019. DAYRELL, Juarez; CARRANO, Paulo. Juventude e ensino médio: quem é este aluno que chega à escola. In: DAYRELL, Juarez; CARRANO, Paulo; MAIA, Carla Linhares. (Org.). Juventude e ensino médio: sujeitos e currículos em diálogo. Belo Horizonte: UFMG, 2014. p.101-133

FRIGOTTO, Gaudêncio. Ensino Médio no Brasil: "juventudes" com futuro interditado. Ano XIX, boletim 18. Brasília: 2009. 41 p. Disponível em: <http://portaldoprofessor.mec.gov.br/storage/ materiais/0000012176.pdf>. Acesso em: 05 maio 2019.

HALL, Stuart. Identidade cultural na pós-modernidade. 3. ed. Rio de Janeiro: DP\&A, 1999.

IBGE. Diretoria de Pesquisas, Coordenação de População e Indicadores Sociais. 2018. Disponível em: <http:// cidades.ibge.gov.br/xtras/perfil.php?codmun=521190>. Acesso em: 25 maio 2018.

LUDKE, Menga; ANDRE, Marli Eliza Dalmazo Afonso de. Pesquisa em Educação: abordagens qualitativas. São Paulo: EPU, 1986.

MITTLER, Peter. Educação Inclusiva: contextos sociais. Porto Alegre: Artmed, 2003.

ONU. Declaração Universal dos Direitos Humanos. Assembleia Geral das Nações Unidas em 10 de dezembro de 1948. Disponível em: < http://www.direitoshumanos.usp.br/index.php/Declara\%C3\%A7\%C3\%A3oUniversal-dos-Direitos-Humanos/declaracao-universal-dos-direitos-humanos.html>. Acesso em: 30 maio 2019.

SANTOS, Boaventura de Sousa. Direitos humanos: o desafio da interculturalidade. Revista Direitos Humanos, Brasília, n. 2, p. 10 - 18, jun. 2009. Disponível em: <http://www.boaventuradesousasantos.pt/ media/Direitos\%20Humanos_Revista\%20Direitos\%20Humanos2009.pdf>. Acesso em: 25 nov. 2019.

SPÓSITO, Marília P. O Estado da arte sobre juventude na pós-graduação brasileira: Educação, Ciências Sociais e Serviço Social (1999-2006). Belo Horizonte: Argumentum, 2009.

UNESCO. Coordenadoria Nacional para a Integração da Pessoa Portadora de Deficiência (CORDE). Declaração de Salamanca de princípios, política e prática para as necessidades educativas especiais. Brasília: UNESCO, 1994. Disponível em: <http://portal.mec.gov.br/seesp/arquivos/pdf/salamanca.pdf>. Acesso em: 01 maio 2019.

UNESCO. Declaração mundial sobre educação para todos. Plano de ação para satisfazer as necessidades básicas de aprendizagem. Jomtien, Tailândia, (UNESCO, 1990). Disponível em: <http://www.unicef. org/brazil/pt/resources_10230.htm>. Acesso em: 08 jan. 2020.

ZARDO, Sinara Pollom. Direito à educação: a inclusão de alunos com deficiência no ensino médio e a organização dos sistemas de ensino. Brasília, 2012. 378 p. Tese (Doutorado em Educação) - Programa de Pós-Graduação em Educação, Faculdade de Educação, Universidade de Brasília, Brasília, 2012. Disponível em: <https:// repositorio.unb.br/handle/10482/12582>. Acesso em: 25 nov. 2019. 